Open Access

\title{
Improved intraocular bioavailability of ganciclovir by mucoadhesive polymer based ocular microspheres: development and simulation process in Wistar rats
}

Usha Ganganahalli Kapanigowda', Sree Harsha Nagaraja², Balakeshwa Ramaiah ${ }^{3 *}$ and Prakash Rao Boggarapu

\begin{abstract}
Background: The poor ocular bioavailability of the conventional eye drops is due to lack of corneal permeability, nasolacrimal drainage and metabolic degradation. To overcome this issue, drug encapsulated in mucoadhesive polymer based ocular microspheres have the advantages of improved drug stability, easy administration in liquid form, diffuse rapidly and better ocular tissue internalization.

Methods: The ganciclovir chitosan microspheres (GCM) were prepared by modified water-in-oil emulsification method. The formulation was optimized and characterized by investigating in vitro release study, release kinetics, XRD and microspheres stability. Ocular irritancy, in vivo ocular pharmacokinetic parameters and histopathology study was evaluated in Wistar rats. The use of pharmacokinetic/pharmacodynamic indices and simulation process was carried out to further ensure clinical applicability of the formulation.

Results: The in vitro release study showed initial burst (nearly $50 \%$ ) in first few minutes and followed Fickian $\left(R^{2}=0.9234\right.$, $\mathrm{n}$-value $=0.2329)$ type of diffusion release mechanism. The XRD and stability studies showed favorable results. The Wistar rat eyes treated with GCM showed significant increase in ganciclovir AUC ( 4.99-fold) and $C_{\max }$ (2.69-fold) in aqueous humor compared to ganciclovir solution and delay in $T_{\max }$. The $\mathrm{C}_{\max } / \mathrm{MIC}_{90}, \mathrm{AUC}_{0-24} / \mathrm{MIC}_{90}$, $A \cup C$ above $\mathrm{MIC}_{90}$ and $T$ above $\mathrm{MIC}_{90}$ were significantly higher in GCM group. The aqueous humor concentration-time profile of ganciclovir in GCM and ganciclovir solution was simulated with every 28.1 and $12.8 \mathrm{~h}$, respectively. The simulated concentration-time profile shows that in duration of $75 \mathrm{~h}$, the ganciclovir solution require six ocular instillations compared to three ocular instillations of the GCM formulation. The photomicrograph of GCM and ganciclovir solution treated rat retina showed normal organization and cytoarchitecture.
\end{abstract}

Conclusions: Correlating with in vitro data, the formulation showed sustained drug release along with improved intraocular bioavailability of ganciclovir in Wistar rats.

Keywords: Franz cells, Superimposition, Release kinetics, Ocular pharmacokinetic, Simulation

\footnotetext{
* Correspondence: balupharmacy@gmail.com

${ }^{3}$ Department of Pharmaceutics, Karnataka College of Pharmacy, \#33/2,

Tirumenahalli, Hegde Nagar Main Road, Bengaluru 560064, Karnataka, India

Full list of author information is available at the end of the article
} 


\section{Background}

Herpes simplex keratitis and cytomegalovirus retinitis have been the most common viral infections observed worldwide [1]. Recurrent and relapse of ocular viral infections can lead to corneal perforation resulting in blindness. The poor bioavailability of the conventional eye drops is due to lack of corneal permeability, nasolacrimal drainage and metabolic degradation. Hence, an optimum treatment must be considered for effective management of ocular viral diseases. Ganciclovir, a broad spectrum antiviral drug was considered to be highly active against cytomegalovirus and herpes simplex virus. Ganciclovir, an acyloguanosine derivative after in vivo administration gets modified into ganciclovir triphosphate. It competitively inhibits the virus deoxyribonucleic acid (DNA) polymerase by impairing the viral DNA synthesis [2].

Ganciclovir requires frequent oral administration, has it shows very poor bioavailability (6-9 \%) [3]. Administration of drug via oral, intravenous or extravascular injection leads to low drug concentration at the site of infected eye [4]. This finding was supported by a study conducted by Young et al. [5], reports that the contralateral retinitis was higher in patients treated with intravenous maintenance therapy of ganciclovir (15-68\%) compared to intravitreous ganciclovir (11\%). Moreover, due to its short half-life, frequent intravitreal injections leads to risk of retinal detachments, hemorrhages, or endophthalmitis. Ganciclovir encapsulated with PLGA microspheres for ocular delivery has been investigated [6]. Reported clinical studies [2, 7, 8] found that the ganciclovir efficacy can be accomplished by formulating the drug as an ophthalmic topical preparation. Hence, a sustained intraocular drug concentration can be achieved by using a desired polymer in the form of microspheres for ocular instillation, which also seems to reduce the ocular toxicities. Ganciclovir combined with chitosan showed two fold increased oral bioavailability [9].

The inherent biological activity of chitosan [poly $(\beta-$ $(1 \rightarrow 4)$-2-amino-2-deoxy-D-glucose)] signifies its role in ocular therapeutics. With various degrees of $\mathrm{N}$ acetylation of glucosamine residues, it is considered as a linear binary heteroploysaccharide composed of $\beta-1,4-$ linked glucosamine. Chitosan being a promising natural biodegradable polymer with hydrophilic in nature improves stability, precorneal retention and enhances interaction with eye mucosa. Moreover, the sustained release, mucoadhesive, in situ gelling, transfection and permeation enhancing properties of chitosan are recognized as few parameters of the polymer suitable for ocular drug delivery. The unique physical properties of chitosan bring transitions in the paracellular and transcellular pathway without disturbing cellular integrity. This innate chitosan property allows the drug to be transported to the inner eye and helps the drug to get accumulated at corneal epithelia $[10,11]$.
Chitosan has the ability to augment intraocular drug penetration by binding with cornea and reversibly loosening the tight corneal conjunctions. Additionally, non toxic, low eye irritation and ability to release the drug at a sustainable fashion qualifies it as one of the ideal polymer for ophthalmic preparation [12, 13]. Chitosan has been used in many ophthalmic preparations such as indomethacin nanoemulsions [14]; indomethacin nanocapsules [15]; cyclosporine A nanoparticles [16]; ofloxacin microspheres [17] and acyclovir microspheres [18]. Zirgan ${ }^{\mathrm{TM}}$ and Virgan ${ }^{\circledR}$ are commercially available ganciclovir ophthalmic gels. Zirgan ${ }^{\mathrm{Ts}}$ has been approved in European countries since 1995 and in 2009 it was approved in United States [1]. Additionally, the ganciclovir implant (Vitrasert) received USFDA approval for the treatment of cytomegalovirus retinitis in immunodeficiency patients.

Intraocular or periocular injections of microparticles or nanoparticles can lead to vitreous clouding and foreign body response. Due to low biodistribution coefficient, the topical administration of ganciclovir has limitations. Frequent administrations of the conventional eye drops are required due to their short retention time and decreased ocular drug bioavailability [19]. Thus, the microspheres are preferred delivery system for ocular drug delivery. The polymeric microspheres have the advantages of easy administration in liquid form, diffuse rapidly and better ocular tissue internalization. The entrapped drug in the form of monolithic-type or reservoir type in the microspheres can act as depot and sustain the release of drug. Hence, literatures $[2,3]$ support the use of ganciclovir as microsphere formulation for improved antiviral effectiveness.

The requirement of ganciclovir ocular preparation for topical application with better therapeutic efficacy and good safety profile was evident. Thus, this study was an attempt to investigate formulation of ganciclovir using mucoadhesive polymer intended for sustained and improved intraocular delivery. The preparation was characterized by in vitro drug release, release kinetics, X-ray diffraction (XRD) and stability study. Further, ocular irritancy, in vivo ocular pharmacokinetic, histopathology along with pharmacokinetic/ pharmacodynamic indices and simulation process was utilized to identify the efficacy and tolerability of the optimized formulation.

\section{Materials and methods \\ Materials}

Ganciclovir was acquired as a gift sample from Dr. Reddys Laboratories, Hyderabad, India. Chitosan (93 \% deactylation) was purchased from Yarrow Chem Products, Mumbai, India. Other reagents used were of analytical grade.

\section{Analytical method}

Reverse-phase high performance liquid chromatography (RP-HPLC) was used for quantitative analysis of ganciclovir 
[20]. The C8 column $(15 \mathrm{~cm} \times 4.6 \mathrm{~mm} ; 5 \mu)$ was utilized for the analysis. The mobile phase consisted of mixture of $0.1 M$ sodium dihydrogen phosphate monohydrate and $0.04 M$ triethylamine in the ratio of $50: 50$ (pH maintained at 6.6). The column temperature was retained at $40{ }^{\circ} \mathrm{C}$. The injection volume was $20 \mu \mathrm{L}$ and the flow rate was maintained at $1 \mathrm{~mL} / \mathrm{min}$. The sample was detected using UV at $254 \mathrm{~nm}$. The acyclovir was considered as an internal standard. The standard calibration curve was linear in the concentration range of 50 to $1000 \mathrm{ng} / \mathrm{mL}$.

\section{Experimental design}

The central composite design was used to optimize ganciclovir loaded chitosan microspheres (GCM) by altering variable factors and their effect on encapsulation efficiency and $12^{\text {th }}$ hour in vitro drug release. The model contained eight factorial points, six axial points and six centre points with total 20 experiments. The mean value was set as 0 and, +1 and -1 was considered as higher and lower levels for each factor respectively. The selected factors with their levels along with optimized levels are summarized in Tables 1 and 2.

\section{Preparation of optimized GCM}

The optimized GCMs intended for ocular sustained release were prepared by modified water-in-oil emulsification method [21]. Seven hundred and fifty milligrams of $93 \%$ deacetylated chitosan was dissolved in $50 \mathrm{~mL}$ of $1 \%$ $\mathrm{w} / \mathrm{v}$ acetic acid maintained at $\mathrm{pH}$ 2.72. Five hundred milligrams of ganciclovir was added to the above solution with agitation and the mixture was sonicated for $10 \mathrm{~min}$. The resultant mixture was centrifuged $(1000 \mathrm{rpm}, 10 \mathrm{~min})$ to separate any remains of undissolved chitosan. The oil phase consisted of $20 \mathrm{~mL}$ of dichloromethane and $20 \mathrm{~mL}$ of liquid paraffin with $1 \mathrm{~mL}$ of $1 \% \mathrm{v} / \mathrm{v}$ of Span 80 . The aqueous phase was introduced slowly as drop wise in to the oil phase under continuous homogenization at 3000 rpm. Further, the water in oil emulsion was homogenized to crosslink the microspheres with $5 \% \mathrm{v} / \mathrm{v}$ of glutaraldehyde. The emulsion was again added to $20 \mathrm{~mL}$ of pre-heated liquid paraffin at $170{ }^{\circ} \mathrm{C}$ with stirring to remove dichloromethane and aqueous solvent. The formed microspheres were filtered through $0.45 \mu \mathrm{m}$ Millipore filters. To remove residual liquid paraffin, the microspheres was then washed 5-6 times with $100 \mathrm{~mL}$ of diethyl ether and was vacuum dried for $24 \mathrm{~h}$.

\section{In vitro drug release of the optimized GCM}

Using Franz diffusion cells, the in vitro release of ganciclovir from the microspheres was investigated. The molecular weight cut-off of the dialysis membrane was between 12,000-14,000 Da (Himedia Laborateries Pvt. Ltd, Mumbai, India). The dialysis membrane acted as a barrier to separate the donor and acceptor compartment. The simulated tear fluid (STF) was used as the dissolution medium, which was prepared by adding $0.67 \%$ of $\mathrm{NaCl} ; 0.2 \%$ of NaHCO3; $0.008 \%$ of $\mathrm{CaCl}_{2} .2 \mathrm{H}_{2} \mathrm{O}$ and the resultant solution $\mathrm{pH}$ was adjusted to 7.4. A weighed amount of microspheres dispersed in $1 \mathrm{~mL}$ of the STF was kept in the donor compartment. The STF $(100 \mathrm{~mL})$ was filled in the acceptor compartment and stirred magnetically at $100 \mathrm{rpm}$ maintaining the temperature at $37 \pm 0.5{ }^{\circ} \mathrm{C}$ [22]. For a period of $12 \mathrm{~h}, 1 \mathrm{~mL}$ of the sample was withdrawn every hour from the acceptor compartment and subjected to UV spectroscopy scanned at $254 \mathrm{~nm}$. The same amount of the fresh STF was replaced into the acceptor compartment.

\section{Release kinetics of the optimized GCM}

Various models such as first order model (1); Higuchi square root model (2); Baker and Lonsdale (3); KoresmeyerPeppas (4) and; Hixon and Crowell cube root model (5) models were used to study drug release mechanism from the microspheres. The data was fitted to these models and was analyzed using sigma plot.

$$
\begin{aligned}
& Q_{t}=Q_{0} \mathrm{e}^{-k_{1} t} \\
& Q_{t}=k_{H} \sqrt{t} \\
& \frac{Q_{t}}{Q_{\infty}}=1-\frac{6}{\pi^{2}} \exp \left(\frac{-\pi^{2} \times D t}{r^{2}}\right) \\
& Q_{t}=Q_{0}+a\left(\frac{t}{r^{2}}\right)^{n}+b\left(\frac{t}{r^{2}}\right)^{2 n} \\
& \sqrt[3]{Q_{0}}-\sqrt[3]{Q_{t}}=\mathrm{k}_{\mathrm{HC}} t
\end{aligned}
$$

$Q_{t}$ is the total amount of drug released after time (\%);

\begin{tabular}{|c|c|c|c|c|c|c|}
\hline \multirow[t]{2}{*}{ Variable factors } & \multicolumn{5}{|l|}{$\underline{\text { Level }}$} & \multirow{2}{*}{$\begin{array}{l}\text { Optimized } \\
\text { level }\end{array}$} \\
\hline & -1.41 & -1 & 0 & 1 & 1.41 & \\
\hline Chitosan concentration (mg) & 79.55 & 250 & 500 & 750 & 920.45 & 750 \\
\hline Stirring speed (rpm) & 318 & 1000 & 2000 & 3000 & 3682 & 3000 \\
\hline Span 80 volume (mL) & 0.20 & 0.40 & 0.70 & 1.0 & 1.20 & 1.00 \\
\hline
\end{tabular}
$Q_{0}$ the initial amount of drug (\%); $k_{1}$ the first order release rate constant $\left(\mathrm{h}^{-1}\right) ; \mathrm{k}_{\mathrm{H}}$ the rate constant obtained according to the Higuchi equation $\left(\% \mathrm{~h}^{-1 / 2}\right) ; Q_{\infty}$ is the

Table 1 Variable factors with their levels used for optimization of GCM 
Table 2 Response factors with expected and observed values for optimized GCM

\begin{tabular}{llll}
\hline Response factors & Expected value & Observed value & Residual value \\
\hline Encapsulation efficiency (\%) & 81.4 & 80.00 & -1.4 \\
$12^{\text {th }}$ hour in vitro drug release (\%) & 77.27 & 78.00 & 0.73 \\
\hline
\end{tabular}

percent release at infinite time; $D$ is the diffusion coefficient in the polymer in $\mathrm{cm}^{2} / s ; r$ is the radius of the sphere in $\mathrm{cm} ; n$ and $2 n$ are the release exponent for Fickian diffusion and case II transport, respectively; $a$ and $b$ are constants related to the drug and the structural and geometric properties of the microparticles; and $\mathrm{k}_{\mathrm{HC}}$ is the rate constant obtained according to the Hixon and Crowell equation $\left(\% \mathrm{~h}^{-1}\right)$ [23-25].

\section{XRD}

XRD of ganciclovir powder, chitosan and the optimized GCM was performed (Philips XPert Pro, Netherlands) at $40 \mathrm{kV}$ voltage with $30 \mathrm{~mA}$ of the current, utilizing a nickel-filtered $\mathrm{CuK} \alpha$ radiation. With $0.02^{\circ}$ interval, the sample was scanned over a $2 \theta$ range of $10-80^{\circ}$ at a rate of $2^{\circ} / \mathrm{min}$.

\section{Stability study of the optimized GCM}

The stability study was conducted as per ICH Q1AR guideline, intended to test the stability for new substances and product. The optimized preparation was stored at $25 \pm 2{ }^{\circ} \mathrm{C}$ and $60 \pm 5 \% \mathrm{RH}$ for twelve months and at $5 \pm 3{ }^{\circ} \mathrm{C}$ for a period of six months. The required volume of microsphere dispersion was stored in closed glass bottles and sealed tightly. At regular intervals, the sample was subjected for determination of encapsulation efficiency, mean particle size distribution and for any physical changes. The test was carried at three month intervals for a period of 12 months for long term storage condition at room temperature and at $0,2,4$ and 6 months for accelerated condition at refrigeration storage.

\section{In vivo ocular pharmacokinetic studies of the optimized GCM}

Prior to the study, the ethical clearance for in vivo experimental protocol was obtained from Institutional Animal Ethics Committee (IAEC) which is registered under CPCSEA, India. The Wistar rats (male and female) free from ocular defects, 11-13 weeks older and weighing around 180-200 g was utilized for the study.

\section{Ocular irritation}

The microspheres ocular tolerability [26] was evaluated by identifying the ocular irritancy. The $1 \% \mathrm{w} / \mathrm{v}$ of the sample was prepared by dispersing the microspheres in isotonic normal saline (ganciclovir solution) and was immediately used for the study. The GCM sample $(25 \mu \mathrm{L})$ was directly instilled into right eye of the rat and for uniform dispersion on cornea; the rats were forced to wink once. The left eye was instilled with normal saline alone and acted as a control. Post instillation, both the eyes were observed for frequency of winking in $5 \mathrm{~min}$.

\section{In vivo evaluation}

A total of 32 Wistar rats were housed in standard cages and had free access to food and water. The rats were allowed for free head and eye movement. To carry out in vivo study [27], $75 \mu \mathrm{L}(3 \times 25 \mu \mathrm{L}$ drops at $90 \mathrm{~s}$ intervals) of the GCM $(1 \% \mathrm{w} / \mathrm{v})$ was freshly prepared and was immediately instilled with micropipette into lower conjunctival sac of the right eye without touching the eye. The $1 \% \mathrm{w} / \mathrm{v}$ of the ganciclovir solution served as a control and as above mentioned quantity and procedure was instilled to the left eye. At $0.5 \mathrm{~h}, 1 \mathrm{~h}, 1.5 \mathrm{~h}, 2 \mathrm{~h}, 3 \mathrm{~h}$, $4 \mathrm{~h}, 5 \mathrm{~h}, 6 \mathrm{~h}, 12 \mathrm{~h}, 24 \mathrm{~h}$ post ocular instillation, the animal was sacrificed by cervical dislocation and the entire eyes were removed. The aqueous humor from the isolated eyes was separated and was stored in micro centrifuge tubes at $-20{ }^{\circ} \mathrm{C}$ until further analysis. After the process of extraction and isolation, the sample was subjected to the RP-HPLC analysis.

\section{Extraction and isolation}

The in vivo pharmacokinetic estimation of the ganciclovir in aqueous humor was performed as mentioned above by RP-HPLC method. The extracted aqueous humor $(100 \mu \mathrm{L})$ was added to $100 \mu \mathrm{L}$ of $50 \%$ trichloroacetic acid, shaken well and was centrifuged at $2000 \mathrm{~g}$ for $10 \mathrm{~min}$ to deproteinize the sample. The supernatant was neutralized with $50 \mu \mathrm{L}$ of $2 M$ sodium hydroxide and vortexed. Later, the sample was extracted with $5 \mathrm{~mL}$ of chloroform and centrifuged at $3000 \mathrm{~g}$ for $5 \mathrm{~min}$. The extracted sample was mixed with $10 \mu \mathrm{L}$ of the mobile phase. Finally $20 \mu \mathrm{L}$ of the mixture and $20 \mu \mathrm{L}$ of the acyclovir as an internal standard were injected into HPLC system [20].

\section{Pharmacokinetic and Statistical analysis}

The pharmacokinetic parameters were calculated using one compartment open model. The ganciclovir, area under the curve (AUC) in aqueous humor was determined from the beginning of the drop instillation $\left(t_{0}\right)$ to the last observation $\left(t_{\text {last }}\right)$ by linear trapezoidal rule with extrapolation to infinite time. Additionally, ganciclovir half life $\left(t_{1 / 2}\right)$, relative bioavailability, the maximum peak concentration $\left(C_{\max }\right)$ 


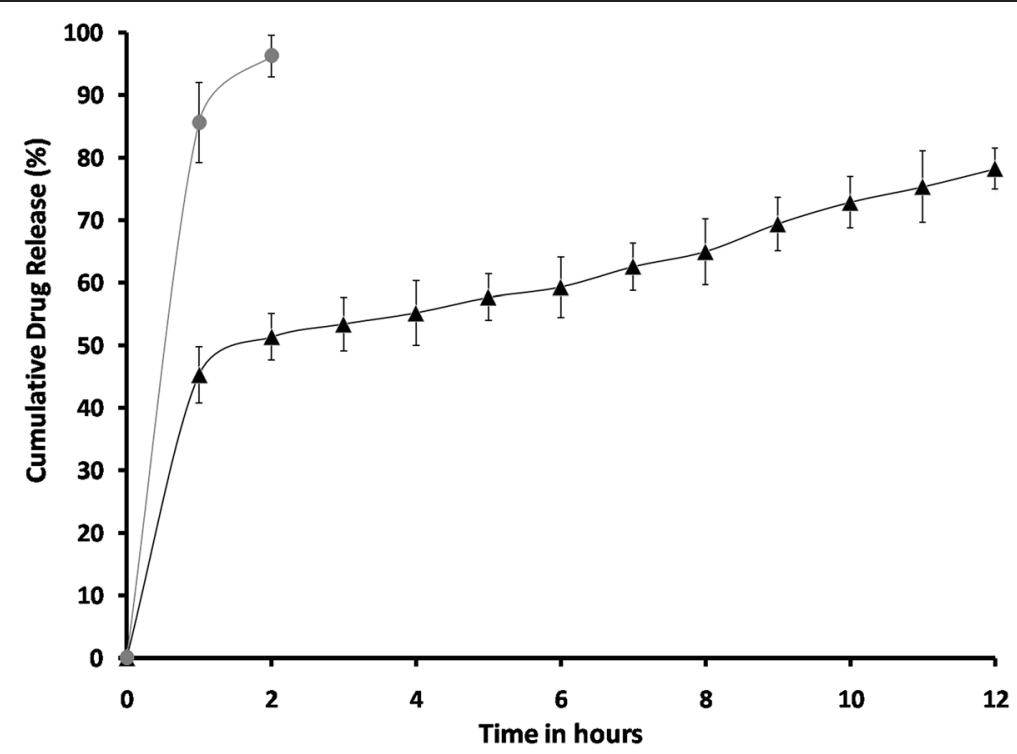

Fig. 1 Cumulative amount of drug released $(\boldsymbol{-})$ GCM and (- - ) ganciclovir solution (bars represent mean \pm SD; $n=3$ )

and time to achieve maximum peak concentration $\left(\mathrm{T}_{\max }\right)$ was also calculated. The terminal rate constant $\left(\mathrm{K}_{\mathrm{e}}\right)$ and apparent absorption rate $\left(\mathrm{K}_{\mathrm{a}}\right)$ of ganciclovir from aqueous humor was estimated from the terminal portions of the respective log (aqueous humor concentration) vs. time linear regression plots [28].

The Kinetica 5.0 PK/PD analysis software was also utilized for the calculation of pharmacokinetic parameters. The estimated pharmacokinetic/pharmacodynamic (PK/ $\mathrm{PD}$ ) indices such as $\mathrm{C}_{\max } / \mathrm{MIC}_{90}, \mathrm{AUC}_{0-24} / \mathrm{MIC}_{90}, \mathrm{AUC}$ above $\mathrm{MIC}_{90}$ and $\mathrm{T}$ above $\mathrm{MIC}_{90}$ was calculated to determine the in vivo efficacy of the GCM. The principle of superimposition using Microsoft excel software was used to evaluate the simulation of aqueous humor concentration- time profile at different dosing interval [29]. Based on the time where the ganciclovir aqueous humor concentration was maintained twice the $\mathrm{MIC}_{90}(1.22 \mu \mathrm{g} / \mathrm{mL})$, the subsequent dose was calculated. Student's $t$ test $(p<0.05)$ was considered for statistical significance.

\section{Histopathology}

The isolated eyes were stored in $10 \%$ formalin and were subjected to histopathological examination. The retina was isolated, dyed with hematoxylin-eosin and

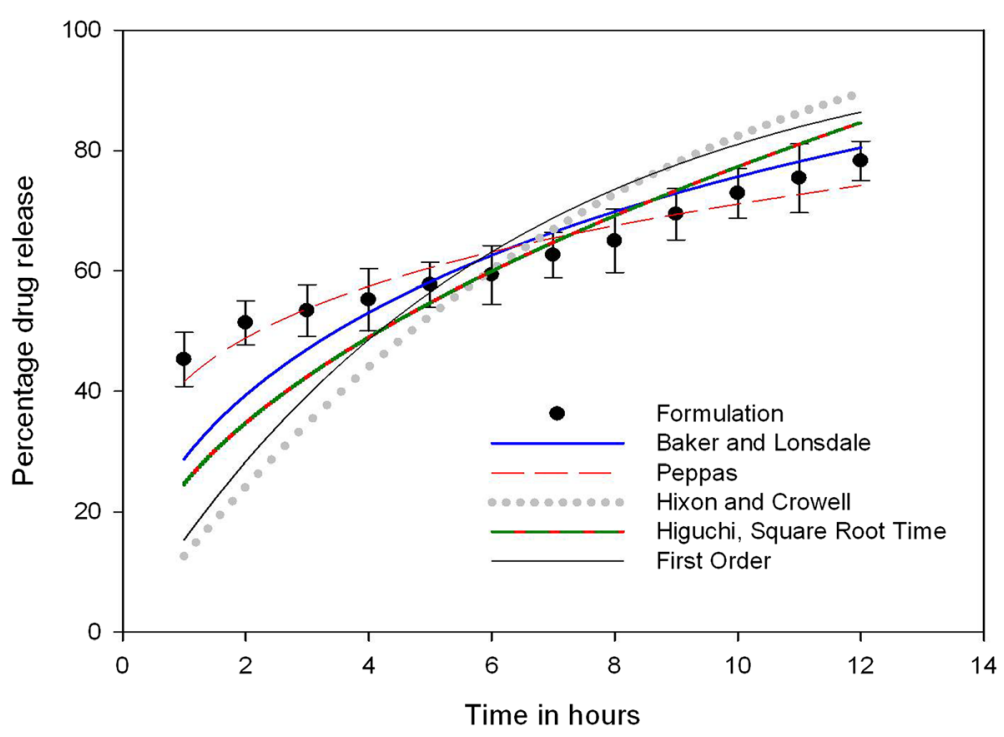

Fig. 2 In vitro release profile of the optimized GCM-curve fitting models (bars represent mean $\pm S D ; n=3$ ) 
Table 3 Stability test observations of the optimized GCM at room temperature

\begin{tabular}{|c|c|c|c|c|c|c|c|c|c|c|c|c|c|c|c|}
\hline \multirow[t]{2}{*}{ Storage } & \multicolumn{5}{|c|}{ Encapsulation efficiency (\%) } & \multicolumn{5}{|c|}{ Mean Particle size $(\mu \mathrm{m})$} & \multicolumn{5}{|c|}{ Physical change } \\
\hline & \multicolumn{5}{|c|}{ Months } & \multicolumn{5}{|c|}{ Months } & \multicolumn{5}{|c|}{ Months } \\
\hline \multirow[t]{2}{*}{$25 \pm 2{ }^{\circ} \mathrm{C}$} & 0 & 3 & 6 & 9 & 12 & 0 & 3 & 6 & 9 & 12 & 0 & 3 & 6 & 9 & 12 \\
\hline & 80.79 & 79.92 & 79.15 & 78.57 & 77.39 & 20.28 & 20.15 & 20.20 & 20.35 & 20.40 & - & - & - & - & - \\
\hline
\end{tabular}

-: No physical change

was observed under light microscopy with $200 \times$ magnification for cytoarchitecture changes.

\section{Results and discussion}

\section{Preparation of the optimized GCM}

The modified water-in-oil emulsification method was found to be suitable and simple technique for encapsulating ganciclovir using chitosan. The degree of chitosan deacetylation and molecular weight are considered to be two fundamental parameters that influence the properties and functionality of chitosan. These parameters along with crystallinity influence chitosan degradation and ocular epithelial cell permeability. More than $60 \%$ of deacetylation of chitosan is considered to be ideal for ocular delivery as decrease in deacetylation leads to decreased water solubility of the polymer. Interestingly, trimethylated chitosan with PEGlation a 3.4-fold increase in its mucoadhesive property was observed, but no such pronounced observation was found in respect to its permeation enhancing property [11]. However, this study used $93 \%$ deacetylated chitosan for the purpose of encapsulation of ganciclovir. On ocular instillation, the liquid form of chitosan transforms into gel form at physiological $\mathrm{pH}$ of 7.4 and significantly helps in longer residence time and biodistribution of the drug on corneal surface. The negatively charged cornea and sclera interacts with positive charged amino groups of the chitosan, hence enhances the ocular bioavailability $[10,30]$. A study by Mathew et al. [31], showed the increased sustained drug release by using optimum glutaraldehyde as cross linking agent. Earlier many studies [32, 33] have successfully prepared chitosan microspheres from emulsion cross-linking method.

\section{In vitro release study of the optimized GCM}

In vitro drug release of the optimized GCM and ganciclovir solution using STF was investigated separately
(Fig. 1). The in vitro data showed biphasic pattern of ganciclovir release from GCM. The initial drug loading followed by marked prolongation of drug residence time was achieved by an initial immediate burst effect (nearly $50 \%$ ) in few minutes and then slower release over few hours (up to $90 \%$ ). The appropriate physicochemical properties of the microspheres help in achieving adequate drug bioavailability and biocompatibility with ocular mucosa. The initial burst release was beneficial in attaining required therapeutic concentration of the drug in negligible time. The rapid and instantaneous initial release was due to the modified water-in-oil emulsification preparation method that resulted in deposition of drug on surface of the microspheres. The drug adhered to the surface of the microspheres are primarily released into aqueous media by desorption and diffusion causing the initial burst $[29,34]$. The decrease in particle size enhances this effect as the formation of large surface area. Similar finding has been observed for different drugs encapsulated in chitosan microspheres [35]. The sustained action in the later stage was due to diffusion of ganciclovir from the polymeric matrix and biodegradation of chitosan. Genta et al., [18] has demonstrated the mucoadhesive and sustain release activity of the chitosan.

\section{Curve fitting analysis of the optimized GCM}

The Fig. 2 shows curve fitting of the optimized formulation in vitro drug release kinetics. Among the models, Koresmeyer-Peppas model was best fitted by significant regression coefficient $\left(\mathrm{R}^{2}=0.9234\right)$. Using Fick's law, Koresmeyer-Peppas model helps in investigating drug release mechanism from the polymeric system in the first $10 \mathrm{~h}$ of the in vitro study. The n-value (0.2329, $p<0.0001$ ) of the optimized formulation was less than 0.45 , indicating Fickian type of diffusion mechanism of drug release. The Koresmeyer-Peppas model explains when the drug release mechanism is a combination of drug diffusion - Fickian transport-, and in Case II

Table 4 Stability test observations of the optimized GCM at refrigeration conditions

\begin{tabular}{|c|c|c|c|c|c|c|c|c|c|c|c|c|}
\hline \multirow[t]{2}{*}{ Storage } & \multicolumn{4}{|c|}{ Encapsulation efficiency (\%) } & \multicolumn{4}{|c|}{ Mean particle size $(\mu \mathrm{m})$} & \multicolumn{4}{|c|}{ Physical change } \\
\hline & \multicolumn{4}{|c|}{ Months } & \multicolumn{4}{|c|}{ Months } & \multicolumn{4}{|c|}{ Months } \\
\hline \multirow[t]{2}{*}{$5 \pm 3{ }^{\circ} \mathrm{C}$} & 0 & 2 & 4 & 6 & 0 & 2 & 4 & 6 & 0 & 2 & 4 & 6 \\
\hline & 80.79 & 80.62 & 79.89 & 79.00 & 20.28 & 20.19 & 20.24 & 20.30 & - & - & - & - \\
\hline
\end{tabular}

-: No physical change 


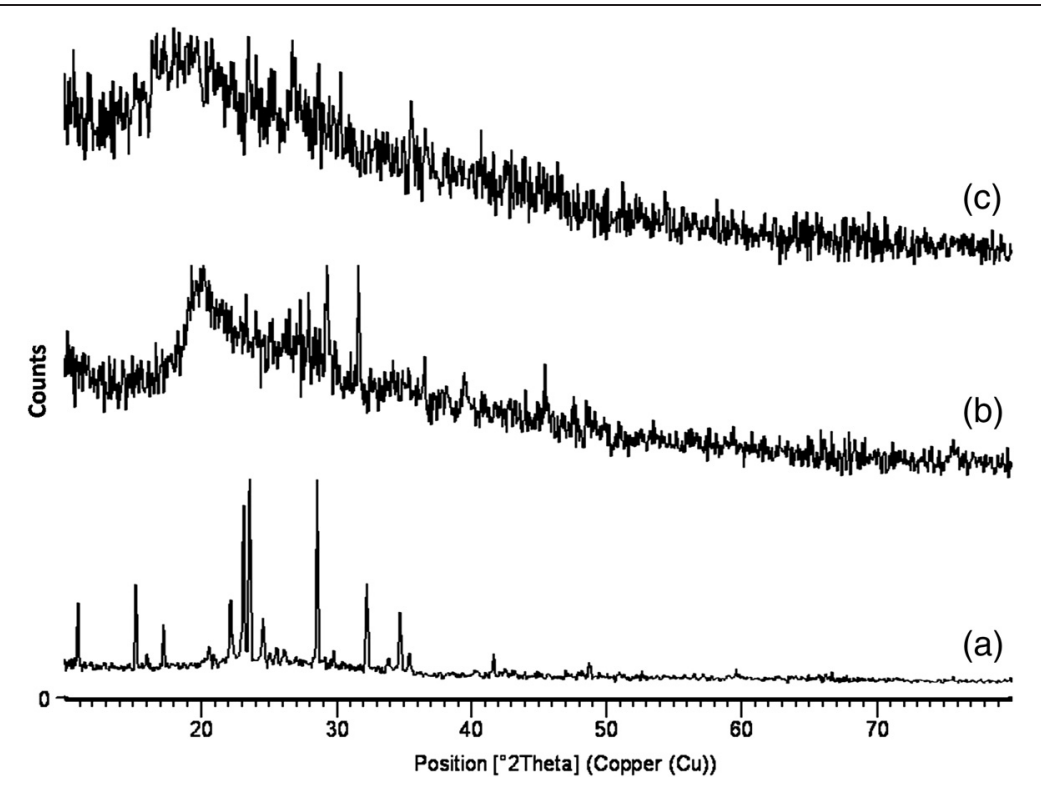

Fig. 3 XRD of (a) ganciclovir; (b) chitosan; (c) optimized GCM

transport - non-Fickian-, controlled by the relaxation of polymer chain. Chitosan polymeric matrix usually represents diffusion and erosion type of drug release [36]. The sustained action of the ocular delivery also depends on the surface characteristics of the microspheres. The positive zeta potential can facilitate an effective adhesion to the cornea surface and also could improve some limitations related to ocular administration, such as prevent tear washout (due to tear dynamics). Subsequently, the positive charge interact with the cell membrane leading in a structural reorganization of tight junction-associated proteins helps in permeation of the drug through corneal surface and improves intraocular drug bioavailability [11, 37].

\section{Stability study of the optimized GCM}

The stability test observations of the optimized GCM at room temperature and refrigeration conditions are depicted in Tables 3 and 4. On storage, no major deviations were observed in the macroscopic characteristics. A slight increase in mean particle size was noted at $25{ }^{\circ} \mathrm{C}$. The XRD spectral characteristics are shown in Fig. 3. On storage, the extent of microsphere sedimentation was not prominent, on

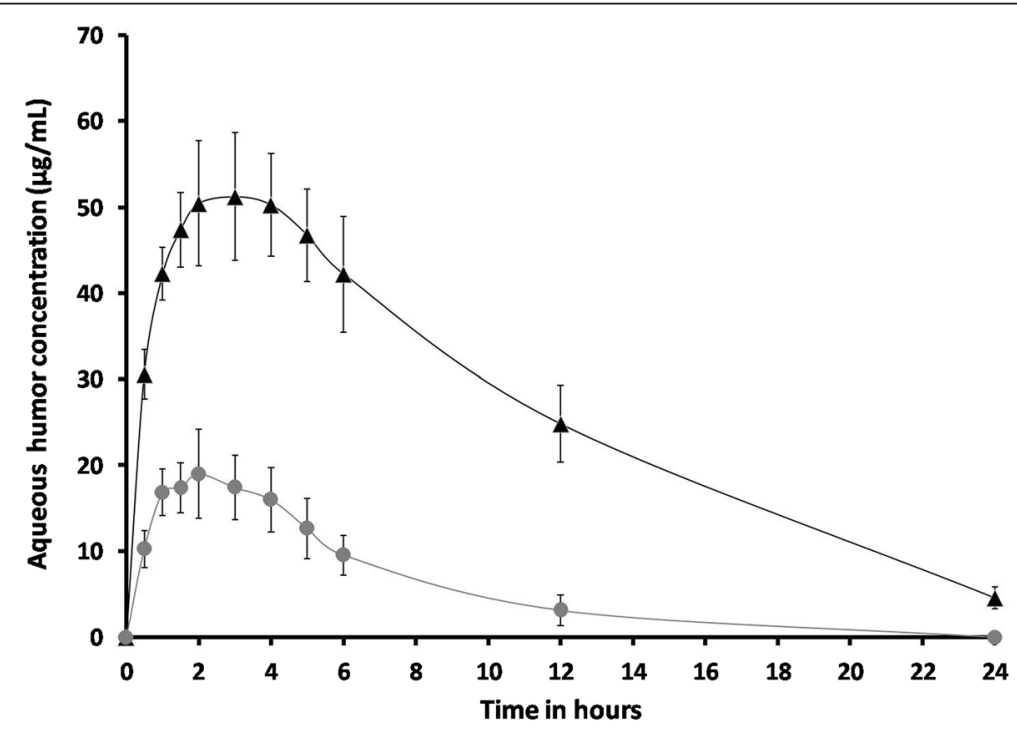

Fig. 4 Aqueous humour concentration of ganciclovir after instillation of $1 \% \mathrm{w} / \mathrm{v}$ of ( $\mathbf{-}$ ) GCM and (--) ) ganciclovir solution (bars represent mean $\pm \mathrm{SD} ; n=3)$ 
Table 5 Aqueous humor pharmacokinetics parameters after ocular instillation of GCM (1\% w/v) and ganciclovir solution (1 \% w/v) in Wistar rat

\begin{tabular}{lllll}
\hline Parameters & Units & GCM & Ganciclovir solution & $P$ value \\
\hline $\mathrm{K}_{\mathrm{a}}$ & $\mathrm{h}^{-1}$ & 0.7252 & 1.2981 & 0.0021 \\
$\mathrm{~K}_{\mathrm{e}}$ & $\mathrm{h}^{-1}$ & 0.1233 & 0.1662 & 0.6270 \\
$\mathrm{~T}_{\max }$ & $\mathrm{h}$ & 3.0 & 2.0 & -- \\
$\mathrm{C}_{\max }$ & $\mathrm{hgmL}^{-1}$ & 51.23 & 18.98 & $<0.0001$ \\
Relative bioavailability $^{\mathrm{a}}$ & unitless & 4.991 & 1.000 & - \\
$\mathrm{t}_{1 / 2}$ & $\mathrm{~h}$ & 5.7654 & 3.5426 & 0.0636 \\
AUC $_{0-24}$ & hugmL $^{-1}$ & 607.187 & 121.634 & $<0.0001$ \\
AUC $_{0-\infty}$ & h $^{-1}$ & $645 \mathrm{ggm}^{-1}$ & 137.692 & $<0.0001$ \\
\hline
\end{tabular}

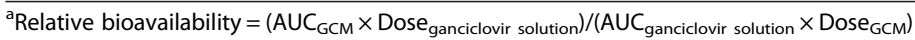

manual agitation they were redispersed easily. XRD spectral characteristic of the ganciclovir pure drug shows many diffraction peaks, indicating the crystallinity of the drug. In contrast, the diffraction peaks were significantly reduced in GCM. XRD of chitosan shows few peaks, which indicates non crystallinity. The GCM formulation showed decreased crystallinity of ganciclovir, which was similar to that of chitosan indicating the incorporation of ganciclovir in the polymer. The increase in mean particle size could be due to increased kinetic energy of system contributing to higher rate of particle collision [26]. Thus, the optimized formula proved to be stable on long term and accelerated storage conditions as well.

\section{In vivo ocular pharmacokinetic studies of the optimized GCM}

The ocular irritation test showed that the GCM sample $(12.0 \pm 1.0 v$ s ganciclovir solution $10.0 \pm 1.0)$ was well tolerated. The ocular pharmacokinetic of the optimized GCM (1\% w/v) was compared with the ganciclovir solution $(1 \% \mathrm{w} / \mathrm{v})$ in Wistar rats. The dose volume and strength of both the samples were same. The $1 \% \mathrm{w} / \mathrm{v}$ strength of both the samples would provide optimum $\mathrm{C}_{\max }$ so as to decrease the nasolacrimal removal of ganciclovir. Subsequently, the relative hydrophilicity of the ganciclovir limits its corneal penetration. The paracellular diffusion of ganciclovir between the tight junctions of the corneal epithelial cells posses a greater challenge [1]. Peyman and Ganiban, [38] showed that the ganciclovir dose upto $400 \mu \mathrm{g} / 0.2 \mathrm{~mL}$ was found to be non toxic to the retina. Hence, to maintain higher concentration of ganciclovir, $1 \% \mathrm{w} / \mathrm{v}$ of the GCM was used in this study for in vivo evaluation. Young et al., [5] study confirms that the injection of greater than $10 \mathrm{mg}$ of ganciclovir into vitreous humor may result in retinal damage. Throughout this study, the ganciclovir concentration in aqueous humor was below the reported toxic ganciclovir concentration in eye. The $0.15 \%$ ophthalmic gel has shown the mean ganciclovir concentration in tears ranging from 0.92 to $6.86 \mu \mathrm{g} \mathrm{mL} \mathrm{m}^{-1}$ without any ocular discomfort [1].

The aqueous humor concentrations of ganciclovir after instillation of $1 \% \mathrm{w} / \mathrm{v}$ of GCM and ganciclovir solution were shown in Fig. 4. The Table 5 illustrates the aqueous humor pharmacokinetic parameters. In comparison with ganciclovir solution, the GCM showed significant increase in AUC ( 4.99-fold). The absorption rate constant $\left(\mathrm{K}_{\mathrm{a}}\right)$ data showed that the GCM trans-corneal permeability was enhanced and was statistically significant than the ganciclovir solution. Subsequently, the terminal rate constant $\left(\mathrm{K}_{\mathrm{e}}\right)$ and $\mathrm{t}_{1 / 2}$ did not alter much. The $\mathrm{C}_{\max }$ of GCM was 2.69-fold of the ganciclovir group $(p<0.0001)$ and the delay in $\mathrm{T}_{\max }$ infers the sustained release of the GCM. The incorporation of ganciclovir into microspheres significantly increased relative bioavailability.

This finding signifies the enhanced binding force of the positively charged GCM to the eye surface. Usually, a mucus film as a thin fluid layer covers the surface of the cornea and conjunctiva. The mucin (high molecular mass glycoprotein) being a primary constituent of mucus carries negative charge at physiological $\mathrm{pH}$. Hence, the positively charged chitosan interact with sialic groups and sulfonic acid substructures of mucin and act as an adhesive force to the eye surface. Upon dissolution, the protonation of amino groups $\left(-\mathrm{NH}_{2}\right)$ of the glucosamine to $-\mathrm{NH}_{3}{ }^{+}$, and the cationic polyelectrolyte readily forms electrostatic interactions with other anionic groups. Thus, the formation of hydrogen bond to the eye surface

Table 6 The estimated pharmacokinetic/pharmacodynamic (PK/PD) indices after ocular instillation of GCM (1 \% w/v) and ganciclovir solution $(1 \% \mathrm{~W} / \mathrm{V})$ in Wistar rat

\begin{tabular}{llcc}
\hline PK/PD indices & Units & GCM & Ganciclovir solution \\
\hline $\mathrm{C}_{\max } / \mathrm{MIC}_{90}$ & unitless & 41.991 & 15.560 \\
AUC $_{0-24} / \mathrm{MIC}_{90}$ & $\mathrm{~h}$ & 497.694 & 99.700 \\
AUC $_{0-24}$ above $\mathrm{MIC}_{90}$ & $\mathrm{~h} \mu \mathrm{gmL}^{-1}$ & 573.518 & 106.239 \\
$T$ above MIC $_{90}$ & $\mathrm{~h}$ & 28.1 & 12.8 \\
\hline
\end{tabular}




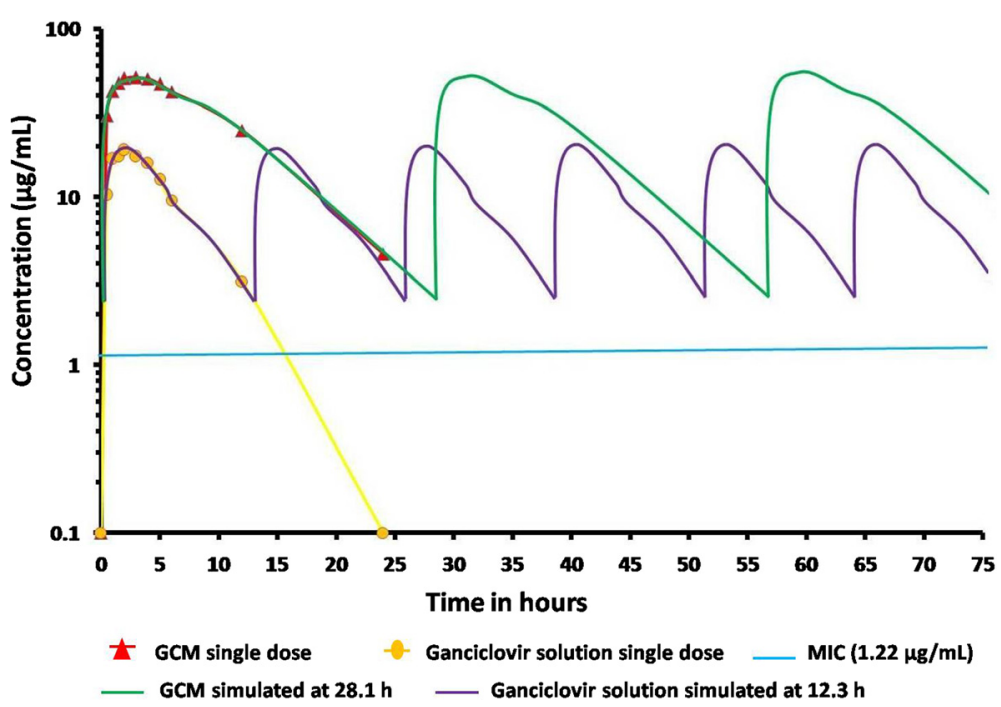

Fig. 5 Simulated ocular concentration time-profile of ganciclovir for $75 \mathrm{~h}$ at a dosing interval of $28.1 \mathrm{~h}$ for GCM and $12.3 \mathrm{~h}$ for ganciclovir solution

which is considerably influenced by cationic free amine and hydroxyl groups of chitosan [11, 28, 30,39].

The estimated pharmacokinetic/pharmacodynamic (PK/ PD) indices after ocular instillation of GCM and ganciclovir solution in Wistar rat are shown in Table 6. The PK/ PD indices play an important role in treatment selection and dosage regimen of ganciclovir as its antiviral activity is concentration dependent. The minimum inhibitory concentration (MIC) solely fails to explain the in vivo activity of an antimicrobial agent. In this study, the $\mathrm{C}_{\max } / \mathrm{MIC}_{90}$ and $\mathrm{AUC}_{0-24} / \mathrm{MIC}_{90}$ of $\mathrm{GCM}$ were maintained higher than the ganciclovir solution. The $\mathrm{C}_{\max } / \mathrm{MIC}$, AUC/MIC, AUC above MIC and T above MIC were higher in the
GCM compared to ganciclovir solution and thus indicates the clinical effectiveness. Moreover, for effective antimicrobial activity, the $\mathrm{C}_{\max } / \mathrm{MIC}_{90}$ and $\mathrm{AUC}_{0-24} / \mathrm{MIC}_{90}$ of GCM should be higher than 10 and 125 , respectively which were complied with GCM formulation [29]. The simulated values also suggest the ideal dosing frequency.

Using the best fit model parameters, the aqueous humor concentration-time profile of GCM and ganciclovir solution was simulated with every 28.1 and $12.8 \mathrm{~h}$, respectively (Fig. 5). The simulated concentration-time profile shows that in duration of $75 \mathrm{~h}$, the ganciclovir solution require six ocular instillations compared to three instillations of the GCM formulation. Thus, GCM minimizes dosing

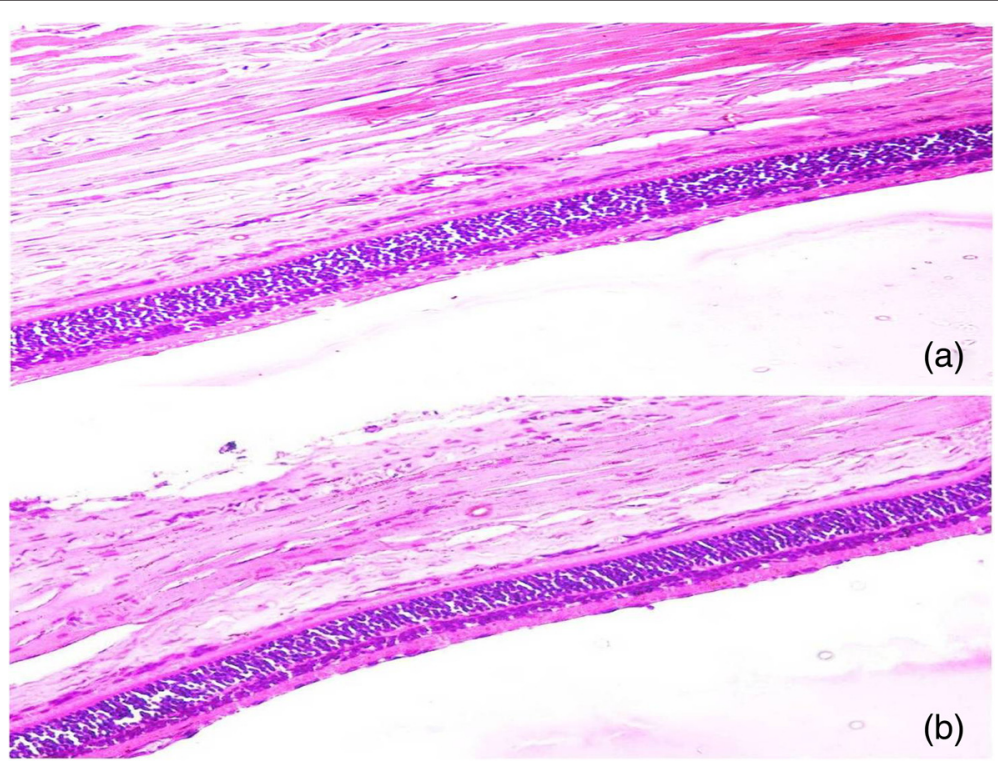

Fig. 6 Photomicrographs of histological slides of rat retina (a) GCM and (b) ganciclovir solution 
frequency by sustained ganciclovir release for better efficacy. The photomicrograph of GCM and ganciclovir solution treated rat retina showed normal organization and cytoarchitecture (Fig. 6). The photomicrograph of GCM and ganciclovir solution showed inner layer of the retina, which was covered by nerve fibers followed by a layer of ganglion cells, an inner plexiform layer, inner nuclear layer, outer plexiform layer, outer nuclear layer, inner and outer segments of the rods, cones and sclera.

\section{Conclusions}

The development of ganciclovir loaded chitosan microspheres was found to be ideal for ocular delivery. The microspheres showed Fickian type of drug release, and the XRD and stability studies showed favorable results. The GCM showed significant increase in AUC and $\mathrm{C}_{\max }$ compared to ganciclovir solution. The $\mathrm{C}_{\max } / \mathrm{MIC}_{90}, \mathrm{AUC}_{0-24} /$ $\mathrm{MIC}_{90}$, AUC above $\mathrm{MIC}_{90}$ and $\mathrm{T}$ above $\mathrm{MIC}_{90}$ were higher in the GCM. Further, the in vivo ocular pharmacokinetic studies along with the histopathology report demonstrated the efficacy and tolerability of the formulation. Hence, the formulation significantly offered sustained drug release and improved intraocular bioavailability of ganciclovir in Wistar rats.

\section{Competing interests}

The authors declare that they have no competing interests.

\section{Authors' contributions}

UGK conceived the study, designed, carried out experiments and drafted the manuscript. SN assisted in design, analysis, interpretation of the data and manuscript plagiarism check. BR coordinated the experiments, involved in XRD, stability studies and drafting the manuscript. PRB participated in the design of the study, interpretation of the data, performed the statistical analysis and revised the manuscript. All authors read and approved the final manuscript.

\section{Acknowledgements}

We are thankful to Prof. Basavaraj Ramnal, Secretary and Dr. Ramesh K, Director, Karnataka College of Pharmacy, Bengaluru, Karnataka, India, for valuable contribution to make this research work possible. We also thank Mr. Lokesh Prasad, DTL, Bengaluru, Karnataka, India, for proof reading the article.

\section{Author details}

'Department of Pharmaceutical Technology, Karnataka College of Pharmacy, \#33/2, Tirumenahalli, Hegde Nagar Main Road, Bengaluru 560064, Karnataka, India. ${ }^{2}$ Department of Pharmaceutical Sciences, College of Clinical Pharmacy, King Faisal University, Al-Ahsa 31982, Saudi Arabia. ${ }^{3}$ Department of Pharmaceutics, Karnataka College of Pharmacy, \#33/2, Tirumenahalli, Hegde Nagar Main Road, Bengaluru 560064, Karnataka, India.

Received: 17 August 2015 Accepted: 12 October 2015

Published online: 24 October 2015

\section{References}

1. Sahin A, Hamrah P. Acute herpetic keratitis: what is the role for ganciclovir ophthalmic gel? Ophthalmol Eye Dis. 2012;4:23-4.

2. Lin T, Gong L, Sun X, Zhao N, Chen W, Yuan H, et al. Effectiveness and safety of $0.15 \%$ ganciclovir in situ ophthalmic gel for herpes simplex keratitis-a multicenter, randomized, investigator-masked, parallel group study in Chinese patients. Drug Des Deve Ther. 2013;7:361-8.

3. Lembo D, Cavalli R. Nanoparticulate delivery systems for antiviral drugs. Antivir Chem Chemother. 2010;21:53-70.

4. Moshfeghi AA, Peyman GA. Micro- and nanoparticulates. Adv Drug Deliv Rev. 2005:57:2047-52
5. Young S, Morlet N, Besen G, Wiley CA, Jones P, Gold J, et al. High-dose $(2000-\mu \mathrm{g})$ intravitreous ganciclovir in the treatment of cytomegalovirus retinitis. Ophthalmol. 1998;105:1404-10.

6. Janoria KG, Mitra AK. Effect of lactide/glycolide ratio on the in vitro release of ganciclovir and its lipophillic prodrug (GCV-monobutyrate) from PLGA microspheres. Int J Pharm. 2007;338:133-41.

7. Charles NC, Steiner GC. Ganciclovir intraocular implant. A clinicopathologic study. Ophthalmol. 1996;103(3):416-21.

8. Teoh SC, Ou X, Lim TH. Intravitreal ganciclovir maintenance injection for cytomegalovirus retinitis:effeicacy of a low-volume, intermediate-dose regimen. Ophthalmol. 2012;119:588-95.

9. Shah P, Jogani V, Mishra P, Mishra AK, Bagchi T, Misra A. Modulation of ganciclovir intestinal absorption in presence of absorption enhancers. L Pharm Sci. 2007:96:2710-22.

10. Alonso MJ, Sanchez A. The potential of chitosan in ocular drug delivery. J Pharm Pharmacol. 2003;55:1451-63.

11. Bernkop-Schnurch A, Dunnhaupt S. Chitosan-based drug delivery systems. Eur J Pharm Biopharm. 2012;81:463-9.

12. Tamboli V, Mishra GP, Mitra K. Biodegradable polymers for ocular drug delivery, in Mitra AK: Advances in Ocular Drug Delivery, Research signpost, Kerala. 2012. p. 65-86.

13. Ye T, Yuan K, Zhang W, Song S, Chen F, Yang X, et al. Prodrugs incorporated into nanotechnology-based drug delivery systems for possible improvement in bioavailability of ocular drugs delivery. Asian J Pharm Sci. 2013;8:207-17.

14. Badawi AA, El-Laithy HM, El Qidra RK. Chitosan based nanocarriers for indomethacin ocular delivery. Arch Pharm Res. 2008;31:1040-9.

15. Calvo P, Vila-Jato JL, Alonso MAJ. Evaluation of cationic polymer-coated nanocapsules as ocular drug carriers. Int J Pharm. 1997;153:41-50.

16. De Campos AM, Sanchez A, Alonso MJ. Chitosan nanoparticles: a new vehicle for the improvement of the delivery of drugs to the ocular surface. Application to cyclosporin A. Int J Pharm. 2001;224:159-68.

17. Di Colo G, Zambito Y, Brugalassi S, Serafinin A, Saettone MF. Effect of chitosan on in vitro release and ocular delivery of ofloxacin from erodible inserts on poly(ethylene oxide). Int J Pharm. 2002;248:115-22.

18. Genta I, Conti B, Perugini P, Pavanetto F, Spadaro A, Puglisi G. Bioadhesive microspheres for ophthalmic administration of acyclovir. J Pharm Pharmacol. 1997;49:737-42.

19. Gaudana R, Ananthula HK, Parenky A, Mitra AK. Ocular drug delivery. AAPS J. 2010;12(3):348-60.

20. Campanero MA, Sadaba B, Garcia-Quetglas E, Azanza JR. Development and validation of a sensitive method for the determination of ganciclovir in human plasma samples by reversed-phase high-performance liquid chromatography. J Chromatogr B. 1998;706:311-7.

21. Park J, Jin H, Kim D, Chug S, Shim W, Shim C. Chitosan microspheres as an alveolar macrophage delivery system of ofloxacin via pulmonary inhalation Int J Pharm. 2013:441:562-9.

22. Miyazaki S, Suzuki S, Kawasaki N, Endo K, Takahashi A. In situ gelling xyloglucan formulations for sustained release ocular delivery of pilocarpine hydrochloride. Int J Pharm. 2001;229:29-36.

23. Dillen K, Vandervoort J, Mooter GV, Ludwig A. Evaluation of ciprofloxacinloaded Eudragit ${ }^{\oplus}$ RS100 or RL100/PLGA nanoparticles. Int J Pharm. 2006;314:72-82.

24. Gibaud S, Al Awwadi NJ, Ducki C, Astier A. Poly(-caprolactone) and eudragit microparticles containing fludracortisones acetate. Int J Pharm. 2004;269:491-508.

25. Huang J, Wigent RJ, Bentzley CM, Schwartz JB. Nifedipine solid dispersion in microparticles of ammonio methacrylate copolymer and ethylcellulose binary blend for controlled drug delivery effect of drug loading on release kinetics. Int J Pharm. 2006;319:44-54.

26. Li X, Nie S, Kong J, Li N, Ju C, Pan W. A controlled-release ocular delivery system for ibuprofen based on nanostructured lipid carriers. Int J Pharm. 2008;363:177-82

27. Gavini E, Chetoni P, Cossu M, Alvarez MG, Saettone MF, Giunchedi P. PLGA microspheres for the ocular delivery of a peptide drug, vancomycin using emulsification/spray-drying as the preparation method: in vitro/in vivo studies. Eur J Pharm Biopharm. 2004:57:207-12

28. Shen Y, Tu J. Preparation and ocular pharmacokinetics of ganciclovir liposomes. AAPS J. 2007:9(3):E371-7.

29. Bhatta RS, Chandasana H, Chhonker YS, Rathi C, Kumar D, Mitra K, et al. Mucoadhesive nanoparticles for prolonged ocular delivery of natamycin: in vitro and pharmacokinetics studies. Int J Pharm. 2012;432:105-12. 
30. Elgadir MA, Uddin MS, Ferdous S, Adam A, Chowdhary AJK, Sarker MZI. Impact of chitosan composites and chitosan nanoparticle composites on various drug delivery systems: A review. J Food Drug Anal. 2014, http:// dx.doi.org/10.1016/j.jfda.2014.10.008

31. Mathew ST, Devi SG, Sandhya KV. Formulation and evaluation of ketorolac tromethamine-loaded albumin microspheres for potential intramuscular administration. AAPS PharmSciTech. 2007;8(1):E1-9.

32. Kumbar SG, Kulkarni AR, Aminabhavi M. Crosslinked chitosan microspheres for encapsulation of diclofenac sodium: effect of crosslinking agent. J Microencapsul. 2002;19(2):173-80

33. Silva CM, Ribeiro AJ, Figueiredo M, Ferreira D, Veiga F. Microencapsulation of hemoglobin in chitosan-coated alginate microspheres prepared by emulsification/internal gelation. AAPS J. 2006;7(4):E903-13.

34. Thakkar H, Sharma RK, Mishra AK, Chuttani K, Murthy RR. Albumin microspheres as carriers for the antiarthritic drug celecoxib. AAPS PharmSciTech. 2005;6(1):E65-73.

35. Bhagav $\mathrm{P}$, Upadhyay $\mathrm{H}$, Chandran S. Brimonidine tartrate-eudragit long-acting nanoparticles: formulation, optimization, in vitro and in vivo evaluation. AAPS PharmSciTech. 2011;12(4):1087-101.

36. Jose S, Fangueiro JF, Smitha J, Cinu TA, Chacko AJ, Premaletha K, et al. Predictive modeling of insulin release profile from cross-linked chitosan microspheres. Eur J Med Chem. 2013;60:249-53.

37. Martinac A, Filipovic-Grcic J, Voinovich D, Perissutti B, Francechinis E. Development and bioadhesive properties of chitosan-ethylcellulose microspheres for nasal delivery. Int J Pharm. 2005;291:69-77.

38. Peyman GA, Ganiban GJ. Delivery systems for intraocular routes. Adv Drug Deliv Rev. 1995;16:107-23.

39. Li N, Zhuang C, Wang M, Sun X, Nie S, Pan W. Liposome coated with low molecular weight chitosan and its potential use in ocular drug delivery. Int J Pharm. 2009;379:131-8.

\section{Submit your next manuscript to BioMed Central and take full advantage of:}

- Convenient online submission

- Thorough peer review

- No space constraints or color figure charges

- Immediate publication on acceptance

- Inclusion in PubMed, CAS, Scopus and Google Scholar

- Research which is freely available for redistribution 